\title{
MYASTHENIA GRAVIS IN CHILDREN AND ANAESTHETIC MANAGEMENT FOR THYMECTOMY
}

\author{
D.W. DavieS, M.B., CH.B., F.R.C.P.(c) \\ AND \\ D.J. STEWARD, M.B., B.S., F.R.C.P. (C)
}

Myasthenia GRavis is a disease characterized by muscle weakness and fatiguability. ${ }^{1}$ The basic defect is at the neuromuscular junction and is associated with a decrease in the quantity of acetyl-choline released at this site. ${ }^{2}$ The disease is considered to be an auto-immune phenomenon. ${ }^{2}$

Anaesthetists have a particular interest in this condition, since they may be consulted regarding diagnostic tests, or required to provide anaesthesia for thymectomy or other surgery, or they may be involved in the treatment of respiratory failure which may complicate this disease.

The incidence of myasthenia gravis has been reported to be 1:40,000. Ten per cent of affected persons are under 16 years of age. ${ }^{3}$

The medical records of patients with myasthenia gravis treated at The Hospital for Sick Children, Toronto, between January 1957 and March 1972, were reviewed. Twenty-two patients whose age varied from 24 hours to 16 years are included. These are tabulated with respect to age, sex, and type in Table $I$.

Myasthenia gravis is of three types. ${ }^{4}$ Neonatal transient myasthenia gravis affects the newborn of mothers with myasthenia gravis. The condition is transient though potentially lethal, and accounts for 2 per cent of cases under 16 years of age. Neonatal persistent myasthenia gravis is recognizable in the first two or three months of life. It accounts for 1 per cent of patients. A family history of myasthenia gravis is rarely obtained. Juvenile myasthenia gravis may occur in two forms; ocular affecting only the extrinsic muscles of the eye and generalized which may affect all voluntary muscles.

Three cases of neonatal transient myasthenia gravis were seen. These infants were the second, third and fourth children of a woman with a 12-year history of myasthenia gravis. Her first child had died, aged 2 days, of bronchopneumonia, and from a review of the history was probably myasthenic. The second and third children were twins. In each case, the diagnosis was clearly established by a definite response to intravenous edrophonium chloride (Tensilon). "Treatment was required for 22 days for each of the twins, and for 42 days for the fourth child. Neostigmine (Prostigmin), $0.25 \mathrm{mg}$, was administered subcutaneously every four hours. As the infants grew older, the dosage was reduced and time between

\footnotetext{
${ }^{\star}$ Tensilon ${ }^{\circledR}$, Prostigmin ${ }^{\circledR}$ : Hoffman-La Roche Limited, Montreal, Quebec.

From the Department of Anaesthesia, The Hospital for Sick Children, and the University of Toronto, Toronto, Canada.

Reprint requests to D.W. Davies, Department of Anaesthesia, The Hospital for Sick Children, 555 University Avenue, Toronto 101, Ontario, Canada.
}

Canad. Anaesth. Soc. J., vol. 20, no. 3, May 1973 
TABLE I

Number and Sex Distributions of Patients with Myasthenia Gravis: The Hospital for Sick CHILdREN 1957 To 1972

\begin{tabular}{lccc}
\hline \multicolumn{1}{c}{ Type } & Female & Male & $\begin{array}{c}\text { Total } \\
\text { Number of Cases }\end{array}$ \\
\hline Neonatal transient myasthenia & 2 & 1 & 3 \\
Neonatal persistent myasthenia & 1 & - & 1 \\
Juvenile myasthenia gravis & 4 & 1 & 5 \\
ocular & 12 & 1 & 13 \\
generalized & 19 & 3 & 22 \\
Total & &
\end{tabular}

TABLE II

Results of Diagnostic Tests

\begin{tabular}{lcc}
\hline \hline \multicolumn{1}{c}{ Test } & Number & Positive \\
\hline Tensilon & 11 & 10 (1 equivocal) \\
Prostigmin & 2 & 2 \\
Curare & 2 & 2 \\
Electromyography & 2 & 2 \\
\hline
\end{tabular}

administrations increased. Doses of anticholinesterase drugs were regulated according to the ability of the baby to suck, and the presence of a brisk Moro reflex. Troublesome secretions occurred in one infant, and were controlled by reducing the dose of anticholinesterase and adding a dose of atropine $(0.1 \mathrm{mg})$ with each dose of neostigmine. One female infant had neonatal persistent myasthenia gravis.

Eighteen cases of juvenile myasthenia gravis occurred in our series, five of the ocular type and 13 of the generalized type. Further study is limited to 12 patients who underwent thymectomy, 11 with juvenile generalized myasthenia gravis and one with neonatal persistent myasthenia gravis.

\section{DiAgNosis}

The diagnostic tests performed are shown in Table II. In ten patients the tensilon test was considered unequivocally positive: the dose of edrophonium chloride varied between $0.04 \mathrm{mg} / \mathrm{kg}$ and $0.4 \mathrm{mg} / \mathrm{kg}$. One patient with an equivocal response $(0.3 \mathrm{mg} / \mathrm{kg})$ had a positive provocative test with d-tubocurarine $(0.005$ $\mathrm{mg} / \mathrm{kg}$ intravenously). Another patient also had a positive provocative curare test ( dose $0.016 \mathrm{mg} / \mathrm{kg}$ ).

Two patients had electromyographic (EMG) studies. Both EMGs showed a progressive fall in evoked potential which improved after injection of edrophonium chloride.

Hyperthyroidism is known to be associated with myathsthenia gravis, ${ }^{2}$ so appropriate screening tests were performed. These were negative in all the patients. No patient had roentgenographic evidence of enlargement of the thymus. 


\section{Thymectomy for Myasthenia Gravis}

The average age at operation was 10.8 years, the range being 2.5 to 16 years. The duration of the illness prior to thymectomy varied from one month to two years, the average being three and a half months.

The best results of thymectomy are reported in young females with a short history of myasthenia gravis and no evidence of thymoma. ${ }^{5}$ At The Hospital for Sick Children, Toronto, thymectomy is undertaken early in the course of the disease. Three of our patients had no trial of medical therapy before operation. The operation was carried out through a median sternotomy in every case. Two patients early in the series had elective tracheostomy performed at the time. In one other early case tracheostomy was necessary 48 hours after thymectomy. The blood loss associated with these procedures is shown in Table III. There were no deaths.

TABLE III

THYMECTOMY FOR MYASTHENIA GRAVIS: BLOOD LOSS

\begin{tabular}{cc}
\hline $\begin{array}{c}\text { Blood loss, } \\
\% \text { estimated } \\
\text { volume }\end{array}$ & $\begin{array}{r}\text { Number } \\
\text { of cases }\end{array}$ \\
\hline$<5$ & 2 \\
$5-10$ & 3 \\
$10-15$ & 4 \\
$15-20$ & 1 \\
$>20$ & 2 \\
Total & 12 \\
\hline
\end{tabular}

\section{Anaesthetic Management for Thymectomy}

Until 1967 all patients were treated with anticholinesterase drugs up to and during operation. Since then these drugs are discontinued for one to four days before operation.

No pre-operative sedation was given. Induction was performed with intravenous thiopentone (2.5\%), 3 to $5 \mathrm{mg} / \mathrm{kg}$, and atropine, $0.02 \mathrm{mg} / \mathrm{kg}$ (to a maximum dose of $0.6 \mathrm{mg}$ ). Anaesthesia was continued with nitrous oxide and halothane. All patients were intubated without the use of muscle relaxants, topical lignocaine spray being used in five patients. Anaesthesia was maintained with nitrous oxide and halothane ( $1 \%$ to $1.5 \%$ ) with controlled intermittent positive pressure ventilation. Prior to 1967, five patients also received low concentrations of trichlorethylene. One patient in the series received $6 \mathrm{mg}$ of d-tubocurarine $(0.1 \mathrm{mg} / \mathrm{kg})$ and one patient received $3 \mathrm{mg}$ of gallamine $(0.1 \mathrm{mg} / \mathrm{kg})$. There were no serious per-operative anaesthetic complications.

\section{Post-Operative Counse and Complications}

Table IV shows the incidence of complications and relates them to the preoperative, per-operative and post-operative use of anticholinesterase drugs. 
TABLE IV

Thymectomy for Myasthenia Gravis: Post-Operative Complications Number

Therapy
$\begin{aligned} & \text { Anticholinesterases administered up to and during } \\ & \text { operation with routine post-operative infusion of } \\ & \text { the drug }\end{aligned}$
$\begin{aligned} & \text { Pre-operative anticholinesterases withdrawn for at } \\ & \text { least } 48 \text { hours or not used; edrophonium chloride } \\ & \text { in small doses used post-operatively as guide to } \\ & \text { therapy }\end{aligned}$
$\begin{aligned} & \text { *Major complication requiring tracheostomy or nasotracheal intubation with institution of } \\ & \text { 1.P.P.V. }\end{aligned}$
+Major respiratory complication resolved without resort to the above means.
\$No major respiratory complication.

TABLE V

Thymectomy for Myasthenia Gravis: Analysis of Three Cases of SERIOUS RESPIRATORY COMPLICATIONS

\begin{tabular}{lc}
\hline \multicolumn{1}{c}{ Complication } & Number \\
\hline Respiratory failure requiring artificial ventilation & 2 \\
Pneumothorax & 1 \\
Lobar atelectasis & 1 \\
Lobar pneumonia & 3 \\
Effusion & 3 \\
Myasthenic crisis & 1 \\
Cholinergic crisis & 1 \\
Retained secretions requiring bronchoscopy & 2 \\
\hline
\end{tabular}

The three patients who had serious post-operative complications were all treated prior to 1967. Their complications are enumerated in Table V.

\section{Discussion}

Experience at The Hospital for Sick Children indicates that edrophonium chloride in a dose of $0.2 \mathrm{mg} / \mathrm{kg}$ is an extremely reliable diagnostic agent if myasthenia is suspected. The one equivocal test listed in Table II was interpreted by a junior resident; a subsequent test proved positive. Since this simple test is so dependable, the more potentially dangerous provocative tests are usually unnecessary.

Jenkins et al. ${ }^{6}$ suggested that withdrawal of anticholinesterase drugs with bed rest for at least 24 hours pre-operatively and no pre-operative sedation are ideal preparation. This has been the routine adopted in this series since 1966. The technique of choice is intravenous induction with thiopentone, maintenance with nitrous oxide and halothane, and controlled ventilation.

The use of muscle relaxants is unnecessary, either for intubation or during maintenance, and offers no advantage. A good intravenous route should be established, since transfusion may be required. The electrocardiogram should be monitored. Bradycardia occurred shortly after intubation in one case and was reversed by an additional dose of atropine.

At the conclusion of the operation the patient is allowed to resume spontaneous ventilation. Ventilation should be assessed clinically and with a respirometer and 
TABLE VI

Thymectomy for Myasthenia Gravis: Response in Twelve Patients

\begin{tabular}{lc}
\hline \hline Response & Number \\
\hline Response A* & 4 \\
Response B† & 5 \\
Response C $\ddagger$ & 3 \\
Response D $\$$ & 0 \\
Response E & 0 \\
Total & 12 \\
\hline
\end{tabular}

${ }^{*}$ Complete remission, drug therapy discontinued.

†Good objective and subjective improvement but continuation of drug therapy on the same or lower dosage.

ISlight objective and/or subjective improvement but large doses of medication necessary.

$\S$ No change or worse.

IDeath.

if it is adequate, the patient should be extubated. Usually the patient will ventilate well immediately following operation. However, the deterioration of muscle-power associated with fatigue should be anticipated within 24 hours of operation. Anticholinesterase drugs will improve muscle power but simultaneously will increase bronchial secretions. ${ }^{7}$ Administration of narcotics is necessary for control of pain, but these patients are sensitive to such drugs and the dose should be reduced accordingly. ${ }^{7}$ Herein lie the dilemmas in the post-operative treatment of these cases.

Routine tracheostomy has been employed in many centres. However, tracheostomy itself may lead to complications. ${ }^{8}$ These are avoidable in many cases if facilities are available for intensive nursing care and continuous medical supervision. Adequacy of ventilation must be evaluated repeatedly, bearing in mind that excessive manipulations and measurements may fatigue the patient unduly. Repeated tensilon tests in the post-operative period are a good guide to therapy. ${ }^{9}$ If small doses of narcotics (for example, pethidine $\mathrm{HCl}$ (Demerol) $0.1 \mathrm{mg} / \mathrm{kg}$ intravenously) are given simultaneously, advantage may be taken of the ensuing period of improved muscle power and analgesia for chest physiotherapy. If ventilation becomes impaired at any time or tracheobronchial secretions become a serious problem, nasotracheal intubation can be instituted. It should be stressed that this management is only possible with 24 -hour intensive care facilities and constant bedside medical supervision.

Rapid improvement is usual after 48 hours and the patient can be uneventfully established on a revised dose of anticholinesterase drug.

The results of thymectomy in this series are comparable with those of Millichamp and Dodge. ${ }^{4}$ Complete remission of the disease occurred in 4 of 12 cases, and objective and manageable improvement in the remaining eight. These results are shown in tabular form in Table VI.

${ }^{*}$ Demerol ${ }^{\circledR}$ : Winthrop Laboratories, Aurora, Ontario. 


\section{SUMMARY}

Records of 22 patients with myasthenia gravis treated at The Hospital for Sick Children, Toronto, between January 1957 and March 1972 were reviewed. Three cases of neonatal transient myasthenia gravis were treated with anticholinesterase drugs. Eleven patients with juvenile generalized myasthenia gravis and one with neonatal persistent myasthenia gravis underwent thymectomy.

The discontinuation of anticholinesterase treatment for at least 24 hours prior to operation and the use of small doses of edrophonium in the first four post-operative days decrease the incidence of complications. Complete remission occurred in four cases and objective improvement in eight. Thymectomy without elective tracheostomy is only possible with 24-hour intensive care facilities and constant medical supervision.

\section{RÉSUMÉ}

Nous avons revu les dossiers de 22 malades souffrant de myasthénie grave et traités à l'hôpital "Sick Children" de Toronto entre janvier 1957 et mars 1972. Trois cas de myasthénie grave néonatale transitoire ont été traités avec des médicaments anticholinestérasiques. Onze malades souffrant de myasthénie grave juvénile généralisée et un malade souffrant de myasthénie grave néonatale persistante ont subi une thymectomie.

L'arrêt du traitement aux anticholinestérasiques durant au moins 23 hres avant l'opération et l'usage de petites doses d'édrophonium la première journée après l'opération ont diminué la fréquence des complications. Chez 4 malades il est résulté une rémission complète et, chez huit autres, une amélioration objective. La thymectomie sans une trachéotomie élective n'est possible que si l'on dispose des facilités des soins intensifs durant 24 heures et d'une surveillance médicale constante.

\section{ACKNOWLEDGEMENT}

The authors wish to thank the surgeons, Dr. J. Fallis, Dr. J. Simpson, and Dr. S. Ein, who permitted their cases to be reviewed.

\section{REFERENCES}

1. Adams, R.D. Episodic muscular weakness, in Harrison, T.R., Wintrobe, M.M., Thorm, G.W., \& Adams, R.D., et al. Harrison's principles of internal medicine, ed. 6, New York, MeGraw-Hill, 1910-1913 (1970).

2. Pathogenesis of Myasthenia Gravis (editorial). Br. Med. J. 2: 1 (1971).

3. MCClelland, R.M.A. The myasthenic state and the myotonic syndrome. Br. J. Anaesth. 32: $81(1960)$.

4. Millichamp, J.G. \& Dodge, P.R. Diagnosis and treatment of myasthenia gravis in infancy, childhood, and adolescence: a study of 51 patients. Neurology 10: 1007 (1960).

5. SLOAN, W.E. The thymus in myasthenia gravis with observations on the normal anatomy and histology of the thymus. Surgery 13: 154 (1943).

6. Jenkins, L.C., Chang, J., \& Saxton, G.D. Myasthenia gravis: anesthetic and surgical management of the patient undergoing thymectomy. Can. Med. Assoc. J. 93: 198 (1965).

7. HEAD, J.M. Respiratory failure after thymectomy for myasthenia gravis. Ann. Surg. 160: $123(1964)$.

8. Newman, M.M. Tracheostomy. Surg. Clin. North Am. 49: 1365 (1969).

9. Osserman, K.E. Myasthenia gravis, in Gellis, S.S. \& Kagan, B.M. Current pediatric therapy. Philadelphia, W.B. Saunders \& Co., 4: 643 (1970). 